\title{
THE FUNDAMENTAL THEOREM OF SIMPLE HARMONIC FUNCTIONS
}

\author{
SAFWAN R. AREKAT
}

(Communicated by Ariel Barton)

\begin{abstract}
The defining relation for a one-dimensional real-valued simple harmonic function designated as cine (pronounced "scene" and symbolized $\operatorname{cin}(x))$ is introduced as $\frac{d}{d x} \operatorname{cin}(x)=\operatorname{cin}(x+p)$. It is theorized that this definition of the derivative as the function itself translated on the real line by a certain positive number $p$ is a sufficient condition for proving that $\operatorname{cin}(x)$ also satisfies the one-dimensional oscillator equation $\frac{d^{2}}{d x^{2}} \operatorname{cin}(x)=-\operatorname{cin}(x)$. A proof of this hypothesis is provided by establishing the continuity, differential, and boundedness properties of $\operatorname{cin}(x)$ and all of its higher-order derivatives and antiderivatives, while relying critically on Roe's characterization of the sine function. The cine function enables the adoption of independent non-circular definitions of the trigonometric functions sine and cosine. The properties of cine are investigated, and trigonometric symmetries and identities are derived directly from the defining relation and its corollaries. A formulation for the unique solution of the function is proposed. Several useful operational theorems are stated and proved. The function is applied to solve problems in trigonometry and physics.
\end{abstract}

\section{INTRODUCTION}

The importance of oscillations in science and technology cannot be overestimated. Indeed, the subject is so familiar to mathematicians, physicists, and engineers that it needs little introduction. While their origin extends back to antiquity in describing triangles and geometry, the sine and cosine functions have evolved in concept, definition, and usage. They constitute the simplest mathematical description of spatial and temporal periodic oscillations, namely the simple harmonic function. It was Leonhard Euler who first recognized that the simple harmonic motion of a forced mechanical oscillator could be described by transcendental functions of time which he defined analytically to be the sine and the cosine functions [1]. The properties and the identities of these functions were not necessarily determined from line segments, circles, or triangles any longer, but from the defining differential equations [2]. This ushered in the mathematical techniques of analytical trigonometry. The consistency between the analytically obtained and the geometrically obtained properties was convincing of the validity of the new functions, and very satisfying as well. Later, Euler advanced the functions further by establishing their close and useful relationship with the complex exponential function. Powerful

Received by the editors August 9, 2019, and, in revised form, April 19, 2020.

2010 Mathematics Subject Classification. Primary 42Axx.

Key words and phrases. Simple harmonic functions, trigonometric functions, trigonometric symmetry, sine, cosine, cine. 
techniques based on analytical trigonometry, the Fourier theorems in particular, found immense applicability in mathematics and scientific fields. The sine and the cosine functions have become deeply rooted central paradigms in mathematics.

The history of mathematics is characterized by an incremental evolution in methods and concepts. Even in recent times, the characterization of the trigonometric functions continues to advance toward completeness. A few decades ago, Roe [3] had arguably provided the most important contribution to advancing our understanding of trigonometric functions in a very long time. Roe's characterization can be summarized as follows. Any function $f(x)$ on the real line with the property that all its derivatives and antiderivatives are uniformly bounded must be a solution to the one-dimensional oscillator equation

$$
\frac{d^{2}}{d x^{2}} f(x)=-f(x)
$$

which is necessarily satisfied by simple harmonic oscillations with period $2 \pi$. This striking argument for characterization by boundedness was hypothesized and proved by Roe and expanded by other studies. Most notably, Strichartz [4] generalized it for higher dimensions and Howard [5] made it encompass complex functions. We quote Roe's theory below because it is critically important for our own theory. In his paper [3], Roe proves the following.

Theorem 1.1. Let $\left\{f^{(n)}\right\}_{n=-\infty}^{n=\infty}$ be a two-way infinite sequence of real-valued functions defined on the real line $\mathcal{R}$. Assume that $f^{(n+1)}(x)=(d / d x) f^{(n)}(x)$ and that there is a constant $M$ such that $\left|f^{(n)}(x)\right| \leq M$ for all $n$ and $x$. Then $f^{(0)}(x)=$ a $\sin (x+\phi)$ for some real constants a and $\phi$.

The present paper continues the effort toward a completeness of our understanding of trigonometric functions. Herein, the concepts of sine and cosine functions are re-evaluated through the fine-tuning of their defining relations. We show that one of the properties of the sine and cosine functions, namely their translational symmetry, can be promoted to a fundamental defining relation. In order to avoid confusion with the longstanding notions of sine and cosine, we define a new primary function cine (pronounced "scene" and symbolized cin $(x)$ ). The sine and cosine functions can then be re-defined as translations of this function.

The main aim in the present paper is to prove that the real-valued function $\operatorname{cin}(x)$ with the property

$$
\frac{d}{d x} \operatorname{cin}(x)=\operatorname{cin}(x+p),
$$

satisfies the conditions in Roe's theorem to qualify as a solution to the oscillator equation (1.1). We use a slightly different formulation from that used by Roe, but eventually we recast it into Roe's notation for comparison. We investigate the numerical and symmetry properties of the cine simple harmonic function, relating it to the trigonometric functions sine and cosine, and we derive trigonometric identities and properties relying only on the fundamental relation and its development, without resorting to geometry, power series expansions, or complex exponential functions. We then propose a formulation for cine that is suitable for practical calculations, apply it to two selected problems, and discuss the advantages of using this new function. 


\section{THE THEOREM}

Theorem 2.1 (The fundamental theorem of simple harmonic functions). Let the real-valued function cin $(x)$ be defined on the real line $\mathcal{R}$, and let it satisfy the relation $\frac{d}{d x} \operatorname{cin}(x)=\operatorname{cin}(x+p)$ for $p \in \mathcal{R}$ and $\forall x \in \mathcal{R}$. Then

$$
\frac{d^{2}}{d x^{2}} \operatorname{cin}(x)=-\operatorname{cin}(x) \text { and } p=\frac{\pi}{2} .
$$

Proof. To prove that $\operatorname{cin}(x)$ is compatible with Roe's theory, we must investigate the continuity, differentiability, antidifferentiability, and boundedness of $\operatorname{cin}(x)$ and its differentially related functions.

Lemma 2.2. The function cin $(x)$ is infinitely differentiable; cin $(x) \in C^{\infty}$.

Proof. The fundamental relation $\frac{d}{d x} \operatorname{cin}(x)=\operatorname{cin}(x+p)$ is an explicit statement that $\operatorname{cin}(x)$ is differentiable to first order, with the derivative equal to the function itself translated by a positive real number $p$. Because $\operatorname{cin}(x)$ is differentiable, it is straightforward to conclude by the chain rule that $\operatorname{cin}(x+p)$ is differentiable as well. Therefore, the derivative $\frac{d}{d x} \operatorname{cin}(x)$ is further differentiable to give the second-order derivative $\frac{d^{2}}{d x^{2}} \operatorname{cin}(x)=\operatorname{cin}(x+2 p)$. The existence of all higher-order derivatives can be proved by an iteration of this argument. In general,

$$
\frac{d^{m}}{d x^{m}} \operatorname{cin}(x)=\operatorname{cin}(x+m p)
$$

where $m$ is any positive integer. The order-m derivative of $\operatorname{cin}(x)$ becomes an $\mathrm{m}$-fold translation by $p$ of $\operatorname{cin}(x)$ on the real line. For a positive value of $p$, differentiation corresponds to shifting $\operatorname{cin}(x)$ to the left. We therefore conclude that all higherorder derivatives exist and are continuous.

Lemma 2.3. The function cin $(x)$ is infinitely integrable, with continuous antiderivatives

Proof. The function $\operatorname{cin}(x)$ is differentiable, therefore it is continuous. This is a sufficient condition for the existence of its antiderivative, which is simply the indefinite integral of $\operatorname{cin}(x), \int \operatorname{cin}(x) d x$. We can transform the fundamental relation $\frac{d}{d x} \operatorname{cin}(x)=\operatorname{cin}(x+p)$ by subtracting $p$ from its argument such that $\frac{d}{d x} \operatorname{cin}(x-p)=\operatorname{cin}(x)$, giving

$$
\int \operatorname{cin}(x) d x=\int \frac{d}{d x} \operatorname{cin}(x-p) d x=\operatorname{cin}(x-p)+c_{1},
$$

where $c_{1}$ is a constant of integration. Because it is a translation of the function $\operatorname{cin}(x)$ itself by $-p$, the antiderivative of $\operatorname{cin}(x)$ is continuous, allowing for successive integration. The second-order antiderivative is

$$
\iint \operatorname{cin}(x) d x=\int \frac{d}{d x} \operatorname{cin}(x-2 p) d x=\operatorname{cin}(x-2 p)+c_{1} x+c_{2} .
$$

The existence of all higher-order antiderivatives can be proved through an iteration of the functional-translation integration procedure, while recognizing the continuity of the integration polynomials. In general, we have that

$$
\left(\int\right)^{m} \operatorname{cin}(x) d x=\operatorname{cin}(x-m p) \text {. }
$$


Dropping the integration polynomial by setting all constants to zero is necessary for proving the boundedness of a subset of antiderivatives, this being because polynomials in general are not bounded on $\mathcal{R}$. However, this elimination does not contradict the main proposition of the existence of continuous antiderivatives of all orders. In the remainder of this paper, we refer to this unique subset of antiderivatives with eliminated polynomials as the antiderivatives of $\operatorname{cin}(x)$. Therefore, the order-m antiderivative is an $\mathrm{m}$-fold translation by $-p$ of $\operatorname{cin}(x)$ on the real line. For a positive value of $p$, antidifferentiation corresponds to shifting $\operatorname{cin}(x)$ to the right. We therefore conclude that all higher-order antiderivatives exist and are continuous.

Lemma 2.4. The set of real functions $\mathcal{F}$ containing cin $(x)$ and all of its higherorder derivatives and antiderivatives is uniformly bounded on $\mathcal{R}$.

Proof. Let the real line $\mathcal{R}$ be partitioned serially into adjacent closed intervals $I_{n} \equiv$ $[n p,(n+1) p]$, where $n$ is an integer ranging from $-\infty$ to $+\infty$, with $p$ considered to be positive. The intervals overlap on their boundaries and have a uniform width $p$. Therefore, all points on the real line are contained in at least one interval in the set. We begin by studying the properties of the functions in the set $\mathcal{F}$ in the centrally positioned closed interval $I_{0}=[0, p]$. Lemmas 2.2 and 2.3 prove the existence of derivatives and antiderivatives for $\operatorname{cin}(x)$ of any order and that are continuous on $\mathcal{R}$ and hence continuous on $I_{0}$. The boundedness theorem demands that a continuous function defined on a closed interval be bounded on that interval. It follows that $\operatorname{cin}(x)$ and all of its higher derivatives and antiderivatives - namely the elements of $\mathcal{F}$ - are bounded on the chosen interval $I_{0}$. However, this is only the first step because we must also prove the boundedness of the functions in $\mathcal{F}$ in all other intervals $I_{n}$ on the real line. The boundedness theorem could be used again to prove the boundedness of $\mathcal{F}$ on intervals $I_{n}$ in the neighborhood of $I_{0}$. However, this argument breaks down as $x \rightarrow \pm \infty$, without having to consider further the details of the functions in $\mathcal{F}$. Let $x_{n} \in I_{n}$ be any point in the interval $I_{n}$, being related to point $x_{0} \in I_{0}$ through a translation by $n p$ as

$$
x_{n}=x_{0}+n p \text {. }
$$

Now, the order-n derivative of $\operatorname{cin}(x)$, belonging to $\mathcal{F}$ which is given by equation (2.1) is evaluated at $x_{0}$ as

$$
\frac{d^{n}}{d x^{n}} \operatorname{cin}\left(x_{0}\right)=\left.\frac{d^{n}}{d x^{n}} \operatorname{cin}(x)\right|_{x_{0}}=\operatorname{cin}\left(x_{n}\right) \text { for } n>0,
$$

and the order-n antiderivative of $\operatorname{cin}(x)$, belonging to $\mathcal{F}$ which is given by equation (2.2) is evaluated at $x_{0}$ as

$$
\left(\int\right)^{n} \operatorname{cin}\left(x_{0}\right)=\left.\left(\int\right)^{n} \operatorname{cin}(x)\right|_{x_{0}}=\operatorname{cin}\left(x_{n}\right) \text { for } n<0
$$

The crucial argument for boundedness is that the function $\operatorname{cin}\left(x_{n}\right)$ in any interval outside the central interval $I_{0}$ can always be equated to a particular function in $\mathcal{F}$ at a point $x_{0}$ inside $I_{0}$, where the boundedness of all the functions in $\mathcal{F}$ has already been proved. This is enabled via the translational definitions of the derivatives and antiderivatives. In particular, for $n>0$, the value of $\operatorname{cin}\left(x_{n}\right)$ in any interval to the right of $I_{0}$ can be equated to the order-n derivative $\frac{d^{n}}{d x^{n}} \operatorname{cin}\left(x_{0}\right)$ inside $I_{0}$. Because $\frac{d^{n}}{d x^{n}} \operatorname{cin}\left(x_{0}\right)$ is bounded on $I_{0} \forall x_{0} \in I_{0}$, we can conclude that $\operatorname{cin}\left(x_{n}\right)$ must also be bounded on $I_{n} \forall x_{n} \in I_{n}$. Similarly, for $n<0$, the 
value of $\operatorname{cin}\left(x_{n}\right)$ in any interval $I_{n}$ to the left of $I_{0}$ can be equated to the order-n antiderivative $\left(\int\right)^{n} \operatorname{cin}\left(x_{0}\right)$ evaluated inside $I_{0}$. We can similarly conclude that because $\left(\int\right)^{n} \operatorname{cin}\left(x_{0}\right)$ is bounded on $I_{0}$, then $\operatorname{cin}\left(x_{n}\right)$ must also be bounded on $I_{n}$. Because $n$ ranges from $-\infty$ to $+\infty$, the boundedness of $\operatorname{cin}\left(x_{n}\right)$ on any interval $I_{n}$ on the real line can be proved by iterating the values of $n$. Therefore, the function is bounded on the entire real line. We define $M$, a positive real number, as the absolute bound of the function $\operatorname{cin}(x)$, namely

$$
|\operatorname{cin}(x)| \leq M \quad \forall x \in \mathcal{R} .
$$

The proof is concluded by restating that the functions contained in $\mathcal{F}$ are the function $\operatorname{cin}(x)$ and all its derivatives and antiderivatives, which are no more than translations of $\operatorname{cin}(x)$ itself on the real line. Translational symmetry preserves functional shape, thus maintaining the absolute bound $M$ for all the functions in $\mathcal{F}$. This can be written as $\left|\frac{d^{n}}{d x^{n}} \operatorname{cin}(x)\right| \leq M$ and $\left|\left(\int\right)^{n} \operatorname{cin}(x)\right| \leq M \forall x \in \mathcal{R}$ and $\forall n \in \mathbb{Z}$, and we can finally conclude that the set of functions $\mathcal{F}$ is uniformly bounded on $\mathcal{R}$.

For comparison with Roe's theory, we reformulate our conclusion in the notation of Roe as follows. By combining the results of equations (2.3) and (2.4), we have

$$
\frac{d}{d x} \operatorname{cin}(x+n p)=\operatorname{cin}(x+(n+1) p),
$$

with $\mathrm{n}$ being any positive or negative integer or zero. We can write the elements of $\mathcal{F}$ as a two-way infinite sequence of real-valued functions $\left\{\operatorname{cin}^{(n)}\right\}_{n=-\infty}^{n=\infty}$ defined on the real line $\mathcal{R}$ with $n \in \mathbb{Z}$ and satisfying

$$
\operatorname{cin}^{(n+1)}(x)=\frac{d}{d x} \operatorname{cin}(x) .
$$

The notation specifies that $\operatorname{cin}^{(n)}$ is the antiderivative of $\operatorname{cin}^{(n+1)}$ and that the derivatives and antiderivatives of $\operatorname{cin}(x)=\operatorname{cin}^{(0)}$ exist to any order. Specifically, the antiderivatives of $\operatorname{cin}(x)$ are given by the negative values of $\mathrm{n}$, and its derivatives are given by the positive values of $\mathrm{n}$. The sequence $\left\{\operatorname{cin}^{(n)}\right\}_{n=-\infty}^{n=\infty}$ is uniformly bounded on $\mathcal{R}$ and there exists a constant M such that for all $n$ and $x$,

$$
\left|\operatorname{cin}^{(n)}(x)\right| \leq M
$$

We can finally conclude that the function $\operatorname{cin}(x)$ has all the properties of Roe's theorem and is therefore a solution of equation (1.1)

$$
\frac{d^{2}}{d x^{2}} \operatorname{cin}(x)=-\operatorname{cin}(x) .
$$

To complete the proof of our theorem, we must find the numerical value of $p$. By differentiating the above equation twice more, we obtain the fourth-order derivative

$$
\frac{d^{4}}{d x^{4}} \operatorname{cin}(x)=\operatorname{cin}(x)=\operatorname{cin}(x+4 p),
$$

meaning that $\operatorname{cin}(x)$ is a periodic function with period $4 p$. The period of the solution to the second-order equation (1.1) is $2 \pi$, thereby giving $p=\frac{\pi}{2}$. However, other values of $\mathrm{p}$ are possible because of the periodicity of $\operatorname{cin}(x)$. This concludes the proof of our theorem. 


\section{Properties of the Cine function}

In the following discussion, we will interchangeably use the $\frac{d}{d x}$ notation and the prime notation to indicate differtiation. However, the prime notation is used to represent differentiation with respect to the argument of a function. For example, $g^{\prime}(y)=\frac{d}{d y} g(y)$ and $\operatorname{cin}^{\prime}(f(x, y, \ldots))=\frac{d}{d f} \operatorname{cin}(f)=\operatorname{cin}(f+p)$, where $f(x, y, \ldots)$ is a function of the variables $x, y$, etc. Also, for brevity we continue to use the symbol $p$ instead of $\frac{\pi}{2}$.

3.1. Simple harmonic first-order differential equations. The simple harmonic function $\operatorname{cin}(x)$ is defined to satisfy

$$
\frac{d}{d x} \operatorname{cin}(x)=\operatorname{cin}(x+p) \text {. }
$$

Together with the second-order oscillator equation,

$$
\frac{d^{2}}{d x^{2}} \operatorname{cin}(x)=-\operatorname{cin}(x),
$$

$\operatorname{cin}(x)$ must also satisfy the first-order equations

$$
\begin{gathered}
\frac{d}{d x} \operatorname{cin}(x)=-\operatorname{cin}(x-p) \text { and } \\
\frac{d}{d x} \operatorname{cin}(x+p)=-\operatorname{cin}(x) .
\end{gathered}
$$

3.2. Relation to trigonometric functions. $\operatorname{cin}(x)$ is a general solution to the second-order oscillator equation and is similar to $A \sin (x+\phi)$, which is a linear combination of sines and cosines. Our hypothesis allows cin $(x)$ to be defined by a single statement, whereas two statements are needed to define the trigonometric functions sine and cosine. The cine function is the root function for both, and there seems to be an unnecessary redundancy in the need for two defining statements. Traditionally, sine and cosine are defined as satisfying the coupled first-order equations

$$
\begin{gathered}
\sin ^{\prime}(x)=\cos (x), \\
\cos ^{\prime}(x)=-\sin (x),
\end{gathered}
$$

with boundary conditions (BC's) $\sin (0)=0$ and $\cos (0)=1$.

The equations are decoupled in second order such that $\sin (x)$ and $\cos (x)$ each satisfy the second-order differential equation. Novel definitions for $\sin (x)$ and $\cos (x)$ are introduced by comparing the first-order equations (3.1) and (3.3) to the standard statements for $\sin ^{\prime}(x)$ and $\cos ^{\prime}(x)$ above, respectively. By inspection, the trigonometric functions can be restated as

$$
\begin{gathered}
\sin (x) \equiv \operatorname{cin}(x), \\
\cos (x) \equiv \operatorname{cin}(x+p),
\end{gathered}
$$

with BC's $\operatorname{cin}(0)=0$ and $\operatorname{cin}(p)=1$. What is novel here is that both $\sin (x)$ and $\cos (x)$ can now be defined independently of each other, in a direct non-circular fashion, in terms of a single function $\operatorname{cin}(x)$ whose argument is translated by $p$ between them. Furthermore, according to this development, one could eliminate sines and cosines altogether and replace them with only cine functions. However, it is one thing to demonstrate unified theoretical definitions of the trigonometric functions, but advocating a reformulation is a different matter altogether. The 
trigonometric functions have become enormously rooted mathematical paradigms, and only overwhelming analytical, algorithmic, or numerical advantage might make such a reformulation conceivable. In this paper, the cine function itself is the object of investigation, so it is given precedence over the trigonometric functions.

Having the foresight of conventional trigonometric functions and their properties will guide the derivation of the properties and symmetries of $\operatorname{cin}(x)$. However, this will be pursued from the defining differential equations and the properties that are established along the way, without the direct use of trigonometric properties, whether geometric, power series or complex exponential relations.

3.3. Boundary conditions. The existence and uniqueness theorem guarantees unique solutions to linear second-order ordinary differential equations. These are determined by specifying the value of the function and its first derivative at a given point. Since the first derivative of $\operatorname{cin}(x)$ is the function itself shifted by $p$, finding the unique solution for $\operatorname{cin}(x)$ depends on specifying the values of $\operatorname{cin}(x)$ at any two points on the real line that are separated by $p$. The expression for the cine function written as $\operatorname{cin}(x)$ does not possess the free parameters necessary to specify unique solutions. For now, it is instructive from a theoretical standpoint to refrain from the numerical assignment of the BC's. Greater generality in deriving the properties and symmetries of $\operatorname{cin}(x)$ may be achieved by recognizing the need for some definite (but unspecified) BC's. A suitable choice for the BC points could be $x=0$ and $x=p$, in which case we give the BC's symbolically as $\operatorname{cin}(0)$ and $\operatorname{cin}(p)$. This contrasts the conventional approach of needing numerical assignments for the $\mathrm{BC}$ 's for the $\sin (x)$ and $\cos (x)$ in order to deduce their properties.

3.4. Periodicity. As derived above, $\operatorname{cin}(x)$ is a periodic function with period $4 p$, namely

$$
\operatorname{cin}(x)=\operatorname{cin}(x+4 p)
$$

3.5. Translational antisymmetry - $\operatorname{cin}(x)$ is antisymmetric for a translation of its argument by $2 p$. By differentiating $\operatorname{cin}(x)$ twice, we find that

$$
\operatorname{cin}(x)=-\operatorname{cin}(x+2 p) .
$$

3.6. Equidistant extrema and zero crossings. Let the points $x_{m 1}, x_{o 1}$, and $x_{m 2}$ be a sequence of three points for an extremum, a zero crossing, and an extremum of $\operatorname{cin}(x)$, respectively. By repeated differentiation with respect to its argument, we find that

$$
\operatorname{cin}^{\prime}\left(x_{m 1}\right)=\operatorname{cin}\left(x_{m 1}+p\right)=\operatorname{cin}\left(x_{01}\right)=-\operatorname{cin}^{\prime}\left(x_{01}+p\right)=-\operatorname{cin}^{\prime}\left(x_{m 2}\right)=0 .
$$

In other words, the argument increases by a uniform value of $p$ along the sequence.

3.7. Linear independence. The functions $\operatorname{cin}(x)$ and $\operatorname{cin}^{\prime}(x)=\operatorname{cin}(x+p)$ constitute a pair of linearly independent functions on the real line. To show this, assume that they are linearly related by a constant $a \in \mathcal{R}$ such that $\operatorname{cin}(x)=a \operatorname{cin}(x+p)$. Differentiating this gives $\operatorname{cin}(x+p)=-a \operatorname{cin}(x)$, giving $a^{2}=-1$, thereby contradicting the assumption that $a$ is real. 
3.8. The sum of $\operatorname{cin}^{2}(x)$ and $\operatorname{cin}^{2}(x)$ is constant. Taking the first derivative, of the sum of squares, we obtain

$$
\begin{gathered}
\frac{d}{d x}\left(\operatorname{cin}^{2}(x)+\operatorname{cin}^{2}(x+p)\right)=2 \operatorname{cin}(x) \operatorname{cin}(x+p)+2 \operatorname{cin}(x+p) \operatorname{cin}(x+2 p) \\
=2 \operatorname{cin}(x) \operatorname{cin}(x+p)-2 \operatorname{cin}(x+p) \operatorname{cin}(x)=0 .
\end{gathered}
$$

3.9. Arbitrary solutions to the simple harmonic differential equations. Any arbitrary function $f(x)$ that satisfies the second-order equation is a linear combination of $\operatorname{cin}(x)$ and $\operatorname{cin}^{\prime}(x)$, written as

$$
f(x)=\mu \operatorname{cin}(x)+\lambda \operatorname{cin}^{\prime}(x)=\mu \operatorname{cin}(x)+\lambda \operatorname{cin}(x+p),
$$

where $\mu$ and $\lambda$ are any real numbers.

3.10. The central theorem of trigonometry (the sum angle relation). The relation $\operatorname{cin}(x+y)$ is the generalization of the sum of angles for the trigonometric functions, being the central theorem of trigonometry [2]. Here $x$ and $y$ are two independent real variables. Using linear independence, and assuming the existence of differentiable functions $g(y)$ and $h(y)$, we write the expression as

$$
\operatorname{cin}(x+y)=g(y) \operatorname{cin}(x)+h(y) \operatorname{cin}^{\prime}(x) .
$$

Taking the first and second partial derivatives of this expression with respect to $x$ and $y$ gives

$$
\begin{gathered}
\frac{\partial}{\partial x} \operatorname{cin}(x+y)=g(y) \operatorname{cin}^{\prime}(x)-h(y) \operatorname{cin}(x), \\
\frac{\partial^{2}}{\partial x^{2}} \operatorname{cin}(x+y)=-g(y) \operatorname{cin}(x)-h(y) \operatorname{cin}^{\prime}(x), \\
\frac{\partial}{\partial y} \operatorname{cin}(x+y)=g^{\prime}(y) \operatorname{cin}(x)+h^{\prime}(y) \operatorname{cin}^{\prime}(x), \\
\frac{\partial^{2}}{\partial y^{2}} \operatorname{cin}(x+y)=g^{\prime \prime}(y) \operatorname{cin}(x)+h^{\prime \prime}(y) \operatorname{cin}^{\prime}(x),
\end{gathered}
$$

where we have that

$$
\begin{gathered}
\frac{\partial}{\partial x} \operatorname{cin}(x+y)=\frac{\partial}{\partial y} \operatorname{cin}(x+y)=\operatorname{cin}(x+y+p) \\
\frac{\partial^{2}}{\partial x^{2}} \operatorname{cin}(x+y)=\frac{\partial^{2}}{\partial y^{2}} \operatorname{cin}(x+y)=\operatorname{cin}(x+y+2 p) .
\end{gathered}
$$

Combining these relations, the functions $g(y)$ and $h(y)$ must satisfy

$$
g^{\prime \prime}(y)=-g(y), h^{\prime \prime}(y)=-h(y), g^{\prime}(y)=-h(y), \text { and } h^{\prime}(y)=g(y) .
$$

These themselves are simple harmonic equations. Therefore, $g(y)$ and $h(y)$ can be written with real parameters $\alpha, \beta, \gamma$, and $\delta$ as

$$
\begin{aligned}
& g(y)=\alpha \operatorname{cin}(y)+\beta \operatorname{cin}^{\prime}(y), \\
& h(y)=\gamma \operatorname{cin}(y)+\delta \operatorname{cin}^{\prime}(y) .
\end{aligned}
$$

But since $h^{\prime}(y)=g(y)$, we conclude that $\gamma=\beta$ and $\delta=-\alpha$. Finally, the expression for $\operatorname{cin}(x+y)$ can be written as

$$
\begin{aligned}
\operatorname{cin}(x+y)=\alpha \operatorname{cin}(x) \operatorname{cin}(y) & +\beta \operatorname{cin}(x) \operatorname{cin}^{\prime}(y) \\
& +\beta \operatorname{cin}^{\prime}(x) \operatorname{cin}(y)-\alpha \operatorname{cin}^{\prime}(x) \operatorname{cin}^{\prime}(y) .
\end{aligned}
$$


We shall see below that this relation has a central importance in deriving the other properties of cine. The parameters $\alpha$ and $\beta$ are related to the initial conditions $\operatorname{cin}(0)$ and $\operatorname{cin}^{\prime}(0)=\operatorname{cin}(p)$. By setting $y=0$ in the sum relation (3.4), linear independence of $\operatorname{cin}(x)$ and $\operatorname{cin}^{\prime}(x)$ requires that $\alpha=\frac{\operatorname{cin}(0)}{\operatorname{cin}^{2}(0)+\operatorname{cin}^{2}(p)}$ and $\beta=$ $\frac{\operatorname{cin}(p)}{\operatorname{cin}^{2}(0)+\operatorname{cin}^{2}(p)}$. So $\alpha$ and $\beta$ are the initial conditions normalized to the sum of their squares, which must be a non-zero constant for a non-trivial solution. For the special case where this constant is unity, $\alpha$ and $\beta$ become the $\mathrm{BC}$ values themselves, subject to the constraint $\alpha^{2}+\beta^{2}=1$. This situation defines the "cine trigonometric basis". The sum of the squares of a function and its derivative in this basis is unity according to property (3.8), and they constitute a linearly independent pair.

The sum relation (3.4) reduces to the regular sum angle relation for the trigonometric functions for a suitable choice of $\alpha$ and $\beta$ in the trigonometric basis. For example, in the case of $\sin (x)=\operatorname{cin}(x)$ for $\operatorname{cin}(0)=0$ and $\operatorname{cin}(p)=1$, we obtain $\alpha=0$ and $\beta=1$, and they transform the sum relation into

$$
\sin (x+y)=\sin (x) \cos (y)+\cos (x) \sin (y),
$$

which is the usual sum relation for the sine function. Similarly, the cosine sum relation

$$
\cos (x+y)=\sin (x) \sin (y)-\cos (x) \cos (y)
$$

is obtained for the case $\alpha=1$ and $\beta=0$, with $\cos (x)=\operatorname{cin}(x)$.

3.11. Symmetry properties of $\operatorname{cin}(x)$. $\operatorname{cin}(x)$ is symmetric (even) about its extrema and antisymmetric (odd) about its zero crossings. Let $\operatorname{cin}\left(x_{0}\right)=\operatorname{cin}^{\prime}\left(x_{m}\right)=$ 0 , where $x_{0}$ and $x_{m}$ are a consecutive zero crossing and extremum, respectively, with $x_{m}=x_{0}+p$. With real-valued $\mu$ and $\lambda$, the function with negative argument can be expanded as

$$
\operatorname{cin}(-x)=\mu \operatorname{cin}(x)+\lambda \operatorname{cin}^{\prime}(x) .
$$

Taking the derivative, we obtain

$$
\frac{d}{d x} \operatorname{cin}(-x)=-\operatorname{cin}^{\prime}(-x)=\mu \operatorname{cin}^{\prime}(x)-\lambda \operatorname{cin}(x),
$$

yielding

$$
\operatorname{cin}^{\prime}(-x)=-\mu \operatorname{cin}^{\prime}(x)+\lambda \operatorname{cin}(x) .
$$

Consider the sum relation given by equation (3.4)

$$
\begin{aligned}
\operatorname{cin}\left(x_{0}+x\right)=\alpha \operatorname{cin}\left(x_{0}\right) \operatorname{cin}(x) & +\beta \operatorname{cin}\left(x_{0}\right) \operatorname{cin}^{\prime}(x) \\
& +\beta \operatorname{cin}^{\prime}\left(x_{0}\right) \operatorname{cin}(x)-\alpha \operatorname{cin}^{\prime}\left(x_{0}\right) \operatorname{cin}^{\prime}(x) .
\end{aligned}
$$

With $\operatorname{cin}\left(x_{0}\right)=0$ this reduces to

$$
\operatorname{cin}\left(x_{0}+x\right)=\beta \operatorname{cin}^{\prime}\left(x_{0}\right) \operatorname{cin}(x)-\alpha \operatorname{cin}^{\prime}\left(x_{0}\right) \operatorname{cin}^{\prime}(x),
$$

giving

$$
\frac{\operatorname{cin}\left(x_{0}+x\right)}{\operatorname{cin}^{\prime}\left(x_{0}\right)}=\beta \operatorname{cin}(x)-\alpha \operatorname{cin}^{\prime}(x)
$$

from which we can write

$$
\frac{\operatorname{cin}\left(x_{0}-x\right)}{\operatorname{cin}^{\prime}\left(x_{0}\right)}=\beta \operatorname{cin}(-x)-\alpha \operatorname{cin}^{\prime}(-x) .
$$


Combining this with equations (3.5) and (3.6) from above gives

$$
\frac{\operatorname{cin}\left(x_{0}-x\right)}{\operatorname{cin}^{\prime}\left(x_{0}\right)}=(\mu \beta-\alpha \lambda) \operatorname{cin}(x)+(\beta \lambda+\alpha \mu) \operatorname{cin}^{\prime}(x) .
$$

Setting $x=0$ in equations (3.5) and (3.6) gives

$$
\begin{gathered}
\operatorname{cin}(0)=\mu \operatorname{cin}(0)+\lambda \operatorname{cin}^{\prime}(0)=\mu \operatorname{cin}(0)+\lambda \operatorname{cin}(p), \\
\operatorname{cin}^{\prime}(0)=-\mu \operatorname{cin}^{\prime}(0)+\lambda \operatorname{cin}(0)=-\mu \operatorname{cin}(p)+\lambda \operatorname{cin}(0) .
\end{gathered}
$$

Dividing the above two equations by $\operatorname{cin}^{2}(0)+\operatorname{cin}^{2}(p)$ and manipulating yields $\alpha=(\beta \lambda+\alpha \mu)$ and $\beta=(\alpha \lambda-\mu \beta)$, which lead finally to

$$
\frac{\operatorname{cin}\left(x_{0}-x\right)}{\operatorname{cin}^{\prime}\left(x_{0}\right)}=-\beta \operatorname{cin}(x)+\alpha \operatorname{cin}^{\prime}(x) .
$$

By comparing this result to the expression containing $\operatorname{cin}\left(x_{0}+x\right)$ in equation (3.8) above, we obtain

$$
\operatorname{cin}\left(x_{0}-x\right)=-\operatorname{cin}\left(x_{0}+x\right),
$$

from which we conclude that $\operatorname{cin}(x)$ is antisymmetric about its zero crossings. Differentiating this relation, we have

$$
\begin{aligned}
\frac{\partial}{\partial x} \operatorname{cin}\left(x_{0}-x\right) & =-\frac{\partial}{\partial x} \operatorname{cin}\left(x_{0}+x\right), \\
-\operatorname{cin}\left(x_{0}-x+p\right) & =-\operatorname{cin}\left(x_{0}+x+p\right),
\end{aligned}
$$

which confirms that $\operatorname{cin}(x)$ is symmetric about its extrema, namely

$$
\operatorname{cin}\left(x_{m}-x\right)=\operatorname{cin}\left(x_{m}+x\right) .
$$

3.12. Argument inversion, $\operatorname{cin}(-x)$. Following the above symmetry parameterization, particularly the relations $\alpha=(\beta \lambda+\alpha \mu)$ and $\beta=(\alpha \lambda-\mu \beta)$, we can expand $\operatorname{cin}(-x)$ in equation (3.5) using the normalized BC's $\alpha$ and $\beta$, namely

$$
\operatorname{cin}(-x)=\frac{\alpha^{2}-\beta^{2}}{\alpha^{2}+\beta^{2}} \operatorname{cin}(x)+\frac{2 \alpha \beta}{\alpha^{2}+\beta^{2}} \operatorname{cin}^{\prime}(x) .
$$

The odd or even parity of the sine and cosine functions is determined from the appropriate choice of $\alpha$ and $\beta$. For example, setting $\alpha=1$ and $\beta=0$ yields $\operatorname{cin}(-x)=\operatorname{cin}(x)$, with even parity being consistent with $\cos (x)=\operatorname{cin}(x)$ in this case.

3.13. Function with scaled argument, $\operatorname{cin}(k x)$ with constant $k$. With a scaled argument, the function satisfies the equation

$$
\frac{d}{d x} \operatorname{cin}(k x)=k \operatorname{cin}(k x+p)
$$

with

$$
\frac{d^{2}}{d x^{2}} \operatorname{cin}(k x)=k^{2} \operatorname{cin}(k x+2 p)=-k^{2} \operatorname{cin}(k x) .
$$

These define sinusoidal functions that have the characteristics of cine but having a scaled period of $\frac{2 \pi}{k}$. 
3.14. Taylor series expansion. Because $\operatorname{cin}(x) \in C^{\infty}$, the Taylor/Maclaurin series for $\operatorname{cin}(x)$ is convergent and can be expanded as

$$
\operatorname{cin}(x)=\sum_{n=0}^{\infty} \frac{\operatorname{cin}^{(n)}(0)}{n !} x^{n}=\sum_{n=0}^{\infty} \frac{\operatorname{cin}(n p)}{n !} x^{n},
$$

where the derivatives are $\operatorname{cin}^{(n)}(0)=\operatorname{cin}(n p)$. Starting at $n=0$, the derivatives repeat the four-valued sequence $\operatorname{cin}(0), \operatorname{cin}(p),-\operatorname{cin}(0)$, and $-\operatorname{cin}(p)$.

It is worthwhile to speculate that it might be possible to prove the fundamental theorem in this paper, Theorem 2.1. by using only the defining equation (1.2) and the general definition for the Taylor series. Further effort directed towards this end might be justified.

3.15. Numerical values of $\operatorname{cin}(x)$. The numerical values for the cine function can be calculated from the Taylor series expansion above. The values depend on the explicit choice of BCs $\operatorname{cin}(0)$ and $\operatorname{cin}(p)$. Because of the $4 p$ translational symmetry and the $2 p$ antisymmetry, only the values between $x=0$ and $x=p=\frac{\pi}{2}$ need to be calculated; elsewhere, the function is determined from its symmetries. The choice $\operatorname{cin}(0)=0$ and $\operatorname{cin}(p)=1$ coincides with $\sin (x)=\operatorname{cin}(x)$, whose numerical values are well known. A novel way to compute the function numerically is to simultaneously model the two first-order differential equations (3.1) and (3.3), using a simple forward Euler's method that alternates back and forth between progressing values for the two equations.

More relations and identities related to trigonometric functions could be derived using the analytical and algebraic techniques for the relations presented above.

\section{The Unique SOlution REPRESEntation OF THE Cine FUnCtion AND ITS APPLICATION}

In this section, we investigate the practical application of the cine function and whether it offers an advantage over the conventional sine and cosine paradigms. First, we propose a formulation for the unique solution for $\operatorname{cin}(x)$. Then several operational theorems concerning this formulation are presented. The new method is applied to elementary problems in the fields of trigonometry and physics.

4.1. The unique solution representation. In the previous section, several fundamental properties of the general solution $\operatorname{cin}(x)$ were derived by applying the first- and second-order differential equations of Theorem 2.1. As elaborated in section 3.3 , this was achieved whilst floating the values of the boundary conditions $\operatorname{cin}(0)$ and $\operatorname{cin}(p)$. This illustrated the theoretical versatility of the function. However, in order to advance the cine function towards practical mathematical utilization, a formulation that refers to specific values of BC's becomes necessary. In the conventional representation for the general solution $A \sin (x+\phi)$, the amplitude $A$ and phase $\phi$, being determined from the BC's, completely specify the unique solutions. But the values of the BC's do not enter directly in this representation. Contrarily, we shall see that an efficient expression for the unique solution of $\operatorname{cin}(x)$ is possible with the explicit reference to the BC's, but without any need for amplitude or phase.

As previously concluded, assigning the values of $\operatorname{cin}(x)$ at two points on the real line separated by $p$ is sufficient for determining the unique solution. We propose an 
array-like representation that treats this information as parameters inside brackets, being separated by commas, as

$$
\operatorname{cin}\left(x_{o}, x_{o}+p, a, b, x\right)
$$

where the first entry in the brackets $x_{o}$ is the first point on the real line, while $x_{o}+p$ is the second point. The values of the function at these two points follow inside the brackets as $a=\operatorname{cin}\left(x_{o}\right)$ and $b=\operatorname{cin}\left(x_{o}+p\right)$. The last entry is the independent variable of the function, $x$. Because the unique solution does not depend on the particular choice of the two points, we adopt the conventional BC point of $x_{o}=0$ without any loss in generality. Consequently, unless deemed necessary for development or elaboration, the first two entries in the brackets, 0 and $p$, become uniform in all cine expressions, and can therefore be dropped. The unique solution can now be written in a more compact manner as $\operatorname{cin}(a, b, x)$. In this notation, $\operatorname{cin}(a, b, 0)=a$, and $\operatorname{cin}(a, b, p)=b$. With $\operatorname{cin}^{\prime}(0)=\operatorname{cin}(p)$ in mind, we can write the correspondence to the conventional form as

$$
\begin{gathered}
\operatorname{cin}(a, b, x)=A \sin (x+\phi), \\
a=A \sin (\phi), b=A \cos (\phi), \\
A=\sqrt{a^{2}+b^{2}}, \phi=\arctan \left(\frac{a}{b}\right) .
\end{gathered}
$$

Any $\operatorname{cin}(a, b, x)$ can be made an element of the cine trigonometric basis defined in property (3.10), by the normalization $\frac{\operatorname{cin}(a, b, x)}{\sqrt{a^{2}+b^{2}}}$. This gives $\operatorname{cin}(\alpha, \beta, x)$ with $\alpha^{2}+\beta^{2}=1$. For example, we can identify the conventional sine and cosine functions as $\sin (x)=\operatorname{cin}(0,1, x)$ and $\cos (x)=\operatorname{cin}(1,0, x)$ to be an independent pair in the cine trigonometric basis. In fact, there is an infinite number of independent pairs in this trigonometric basis which are obtainable by different choices of $\alpha$ and $\beta$, subject to the constraint $\alpha^{2}+\beta^{2}=1$. The operational theorems that follow demonstrate the appropriateness of this formulation for the unique solution of the cine function and provide the useful tools necessary to develop the formulation further.

Theorem 4.1 (Scaling theorem). A constant amplitude multiplying the cine function is absorbed into the $B C^{\prime} s, C \operatorname{cin}(a, b, x)=\operatorname{cin}(C a, C b, x)$.

Proof. Multiplying a function by the constant amplitude $C$ scales the value of the function at all points in its domain $\mathcal{R}$, including its values at $x=0$ and $x=p$, which become $C a$ and $C b$. But since it can be shown trivially that the scaled function remains a solution of the first- and second-order differential equations of Theorem 2.1, the scaled function itself is recognized as a cine function determined uniquely by its own scaled BC's, $C a$ and $C b$ at $x=0$ and $x=p$, respectively. By using our notation, the scaled function can be written as $\operatorname{cin}(C a, C b, x)$.

Theorem 4.2 (Addition theorem). The sum of two cine functions is a single cine function determined by the sum of the individual $B C$ 's, cin $\left(a_{1}, b_{1}, x\right)+$ $\operatorname{cin}\left(a_{2}, b_{2}, x\right)=\operatorname{cin}\left(a_{1}+a_{2}, b_{1}+b_{2}, x\right)$.

Proof. The well-known principle of superposition states that a linear combination of two solutions to a linear homogeneous differential equation is itself a solution to the same differential equation. This lends to the sum $\operatorname{cin}\left(a_{1}, b_{1}, x\right)+\operatorname{cin}\left(a_{2}, b_{2}, x\right)$ being itself a solution to the first- and second-order differential equations of Theorem 2.1. The sum is therefore a simple harmonic function which can be written 
using a single cine expression. When two functions are added, their values at each point in their domain are added point by point. We apply this to the sum of the functions at the BC points $x=0$, and $x=p$ as

$$
\begin{aligned}
& \operatorname{cin}\left(a_{1}, b_{1}, 0\right)+\operatorname{cin}\left(a_{2}, b_{2}, 0\right)=a_{1}+a_{2} \equiv a_{\text {sum }} \quad \text { at } \quad x=0, \\
& \operatorname{cin}\left(a_{1}, b_{1}, p\right)+\operatorname{cin}\left(a_{2}, b_{2}, p\right)=b_{1}+b_{2} \equiv b_{\text {sum }} \text { at } \quad x=p .
\end{aligned}
$$

A single cine expression for the sum can now be written from its new added BC values of $a_{\text {sum }}$ and $b_{\text {sum }}$ as $\operatorname{cin}\left(a_{\text {sum }}, b_{\text {sum }}, x\right)=\operatorname{cin}\left(a_{1}+a_{2}, b_{1}+b_{2}, x\right)$.

The two theorems above can be combined to yield the general linear superposition relation for an arbitrary number of cine functions as

$$
\sum C_{i} \operatorname{cin}\left(a_{i}, b_{i}, x\right)=\operatorname{cin}\left(\sum C_{i} a_{i}, \sum C_{i} b_{i}, x\right) .
$$

This relation affords a considerable simplification for the superposition of harmonic functions as two trivial numerical sums followed by only a single calculation of cine.

Theorem 4.3 (Shift theorem). Adding a constant $\theta$ to the argument of cine shifts of the $B C$ points as

$$
\operatorname{cin}(0, p, a, b, x+\theta)=\operatorname{cin}(-\theta, p-\theta, a, b, x) .
$$

Proof. By setting $y=x+\theta$, the BC points for $y$ become $-\theta$ and $p-\theta$. The argument of cine is rewritten using symbol $x$, and the expression above is obtained.

Theorem 4.4 (Differentiation theorem). The derivative of the cine function is given by the permutation of its $B C$ 's as $\frac{d}{d x} \operatorname{cin}(a, b, x)=\operatorname{cin}(b,-a, x)$.

Proof. The fundamental first-order relation gives $\frac{d}{d x} \operatorname{cin}(a, b, x)=\operatorname{cin}(a, b, x+p)$. Evaluating the derivative at $x=0$ gives $\operatorname{cin}(a, b, p)=b$, while evaluating at $x=p$ gives $\operatorname{cin}(a, b, 2 p)=-\operatorname{cin}(a, b, 0)=-a$, from the antisymmetry property (3.5). It was shown in Lemma 2.2 that the derivative of the cine function is itself a cine function. Therefore, by inspecting the values of the derivative $b$ and $-a$ at $x=0$ and $x=p$, respectively, we can write the derivative as $\operatorname{cin}(b,-a, x)$.

Theorem 4.5 (Integration theorem). The antiderivative of the cine function is given by the permutation of its BC's as $\int \operatorname{cin}(a, b, x) d x=\operatorname{cin}(-b, a, x)$.

Proof. It was shown in Lemma 2.3 that $\int \operatorname{cin}(a, b, x) d x=\operatorname{cin}(a, b, x-p)$. Evaluating the antiderivative at $x=0$ gives $\operatorname{cin}(a, b,-p)=-\operatorname{cin}(a, b, p)=-b$, from the antisymmetry property (3.5), while evaluating at $x=p$ gives $\operatorname{cin}(a, b, 0)=a$. It was shown in Lemma 2.3 that the antiderivative of the cine function is itself a cine function. Therefore, by inspecting the values of the antiderivative at its $\mathrm{BC}$ values $-b$ and $a$ at $x=0$ and $x=p$, respectively, we can write the antiderivative as $\operatorname{cin}(-b, a, x)$.

4.2. Cine representation for sinusoidal functions. The theory and characteristics of the cine function may be adapted for argument transformation $x \rightarrow$ $k x$, with the modified differential equations encountered in property (3.13). Several adjustments must be made: (a) The period of oscillation in this case will be $\frac{4 p}{k}=\frac{2 \pi}{k}$. (b) The two points for specifying the BC's are to be separated by $\frac{p}{k}$, as $x=0$ and $x=\frac{p}{k}$. (c) The expression for cine retains the frequency $k$ in its argument and is written as $\operatorname{cin}\left(0, \frac{p}{k}, a, b, k x\right)$ or more compactly 
as $\operatorname{cin}(a, b, k x)$, for oscillations of the same frequency. (d) The cine derivative operation becomes $\frac{d}{d x} \operatorname{cin}(a, b, k x)=\operatorname{cin}(k b,-k a, x)$. (e) The integration operation becomes $\int \operatorname{cin}(a, b, k x) d x=\operatorname{cin}\left(\frac{-b}{k}, \frac{a}{k}, k x\right)$. (f) The Taylor/Maclaurin series for $\operatorname{cin}(a, b, k x)$ is given as $\operatorname{cin}(a, b, k x)=\sum_{n=0}^{\infty} \frac{\operatorname{cin}^{(n)}(a, b, 0)}{n !}(k x)^{n}$, where the derivatives repeat the four-valued sequence $a, b,-a$, and $-b$.

With the material and theorems presented above, we are now prepared to demonstrate the application of cine.

4.3. The harmonic addition theorem. In trigonometry, the sum of $B \sin (x)+$ $C \cos (x)$ can be written as a single sine expression $A \sin (x+\phi)$. A proof using trigonometric identities proceeds by using the sine sum angle formula $A \sin (x+\phi)$ $=A \sin (x) \cos (\phi)+A \cos (x) \sin (\phi)$. Equating to the original expression and using the linear independence of $\sin (x)$ and $\cos (x)$ gives $A \cos (\phi)=B$ and $A \sin (\phi)=C$. Squaring the two equations, adding them and factoring out $A$ gives $A^{2}\left(\cos (\phi)^{2}+\sin (\phi)^{2}\right)=B^{2}+C^{2}$, from which we find $A=\sqrt{B^{2}+C^{2}}$. The phase angle $\phi$ is found by dividing $A \sin (\phi)=C$ by $A \cos (\phi)=B$ giving $\tan (\phi)=\frac{C}{B}$ and $\phi=\tan ^{-1}\left(\frac{C}{B}\right)$. One can also solve this using complex exponentials requiring several derivation steps. To contrast, using the definitions for $\sin (x)$ and $\cos (x)$ in terms of cine, and applying the scaling and addition theorems above, we write $B \sin (x)+C \cos (x)=B \operatorname{cin}(0,1, x)+C \operatorname{cin}(1,0, x)=\operatorname{cin}(C, B, x)$. The correspondence equations set (4.1) can be used to show that $A$ and $\phi$ here are the same as above. The cine method involves fewer steps and offers a simpler and more efficient solution.

4.4. Simple harmonic motion. In physics, a particle with mass $m$ subjected to a linear restoring force with constant $s$, executes simple harmonic motion when initially disturbed from equilibrium. The motion is determined from the equation of motion $\frac{d^{2}}{d x^{2}} y(t)=-\frac{s}{m} y(t)$, where $y(t)$ is the particle's displacement to be determined. The initial conditions are usually given as measurements of the initial position $y_{o}$ and velocity $v_{o}$ at $t=0$. The general solution to the motion becomes $y(t)=A \sin (\omega t+\phi)$, where the natural frequency of oscillation is $\omega=\sqrt{\frac{s}{m}}$. Applying the initial conditions yields $y_{o}=A \sin (\phi)$, and $v_{o}=\omega A \cos (\phi)$ - since the velocity is the first derivative of the displacement. Squaring, adding and taking the square root determines the amplitude of the oscillation $A=\sqrt{y_{o}^{2}+\frac{v_{o}^{2}}{\omega^{2}}}$, while the phase is found as $\phi=\tan ^{-1}\left(\frac{\omega y_{o}}{v_{o}}\right)$. On the other hand, if the cine formulation is used, the initial conditions to be recorded for the same experiment should be the displacements $y_{o}$ at $t=0$ and $y_{1}$ at $t=\frac{p}{\omega}=\frac{\pi}{2 \omega}$. The displacement as a function of time can be directly written according to section 4.2 as $y(t)=\operatorname{cin}\left(y_{o}, y_{1}, \omega t\right)$. That is all there is to it. The numerical values of the displacement can be computed directly from the Taylor series as outlined in properties (3.14) and (3.15), and as modified for scaled argument in (4.2). If needed, the cine expression can be converted using equations (4.1) to

$$
y(t)=\sqrt{y_{o}^{2}+y_{1}^{2}} \sin \left(\omega t+\tan ^{-1}\left(\frac{y_{o}}{y_{1}}\right)\right) .
$$

To check correspondence, the value of $y_{1}$ for the same experiment can be diligently calculated from the conventional solution for $y\left(t=\frac{\pi}{2 \omega}\right)$ to give the value of $\frac{v_{o}}{\omega}$. 
When substituted for in the cine solution, it gives the same conventional mathematical expression. The oscillator energy is found as the sum of its potential and kinetic energies, $\frac{1}{2} s y(t)^{2}+\frac{1}{2} m \frac{d y(t)}{d t}^{2}=\frac{1}{2} s \operatorname{cin}\left(y_{o}, y_{1}, \omega t\right)^{2}+\frac{1}{2} m \operatorname{cin}\left(\omega y_{1},-\omega y_{o}, \omega t\right)^{2}$. Factoring $\omega$ from the second term, and $A$ from both terms for normalization, we obtain

$$
\frac{1}{2} s A^{2}\left(\operatorname{cin}\left(\frac{y_{o}}{A}, \frac{y_{1}}{A}, \omega t\right)^{2}+\operatorname{cin}\left(\frac{y_{1}}{A}, \frac{-y_{0}}{A}, \omega t\right)^{2}\right) .
$$

This gives the correct conserved energy term $\frac{1}{2} s A^{2}$, since the two squared cine expressions inside the brackets are an independent pair in the trigonometric basis who's squares add to one, as discussed in property (3.10). We comment that measuring the initial conditions as two consecutive displacements is easier in practice than the simultaneous measurement of displacement and instantaneous velocity, which require different measuring instruments. Again, it is obvious that the cine method for this oscillator problem offers a simpler and more direct way for applying the initial conditions to obtain the unique solution.

\section{Conclusions}

The theorem and discussion presented in this paper are aimed at introducing the simple harmonic function cine and advancing the understanding of the trigonometric functions sine and cosine. It was found that they all satisfy a first-order relation from which the second-order relation follows as a corollary. Several wellknown trigonometric identities and symmetries were re-derived from the differential equations alone without reference to geometry, Taylor series expansions, or complex functions. The formulations and operational theorems that were presented for cine point to distinct advantages in using this new function. With the possibility of developing its properties and identities further, and adopting it for existing analytical theorems, it is not unreasonable to speculate that cine could find applications in numerous fields in modern mathematics, physics, and engineering.

\section{REFERENCES}

[1] V. Katz, A history of mathematics: An introduction, Third Edition., Addison-Wesley, Boston, (2009).

[2] R. Courant, Introduction to Calculus and Analysis, vol. 1. Interscience Publishers, New York, (1965).

[3] J. Roe, A characterization of the sine function, Math. Proc. Cambridge Philos. Soc. 87 (1980), no. 1, 69-73, DOI 10.1017/S030500410005653X. MR.549299

[4] R. S. Strichartz, Characterization of eigenfunctions of the Laplacian by boundedness conditions, Trans. Amer. Math. Soc. 338 (1993), no. 2, 971-979, DOI 10.2307/2154439. MR1108614

[5] R. Howard, A note on Roe's characterization of the sine function, Proc. Amer. Math. Soc. 105 (1989), no. 3, 658-663, DOI 10.2307/2046914. MR942633

Department of Physics, University of Bahrain, Sakheer, Kingdom of Bahrain Current address: P. O. Box 5003, Manama, Kingdom of Bahrain

Email address: s.r.arekat@gmail.com 